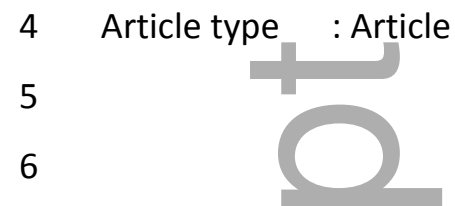

\section{Shifting Diets of Lake Trout in Northeastern Lake Michigan}

8

9 Miles K. Luo

10

17

\section{University of Michigan, School for Environment and Sustainability, 440 Church Street, Ann}

Arbor, Michigan 48109, USA

\section{Charles P. Madenjian*}

U. S. Geological Survey, Great Lakes Science Center, 1451 Green Road, Ann Arbor, Michigan 48105, USA

\section{James S. Diana}

University of Michigan, School for Environment and Sustainability, 440 Church Street, Ann Arbor, Michigan 48109, USA

\section{Matthew S. Kornis and Charles R. Bronte}

U. S. Fish and Wildlife Service, Green Bay Fish and Wildlife Conservation Office, 2661 Scott Tower Drive, New Franken, Wisconsin, 54229, USA

4

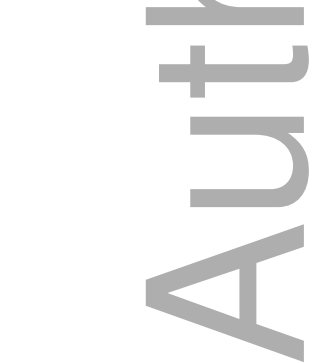

${ }^{*}$ Corresponding author: cmadenjian@usgs.gov

This is the author manuscript accepted for publication and has undergone full peer review but has not been through the copyediting, typesetting, pagination and proofreading process, which may lead to differences between this version and the Version of Record. Please cite this article as doi: $\underline{10.1002 / N A F M .10318}$

This article is protected by copyright. All rights reserved 
Abstract

Prey fish communities in Lake Michigan have been steadily changing, characterized by declines in both the quantity and quality of Alewife Alosa pseudoharengus. To evaluate concurrent changes in the diet of Lake Trout Salvelinus namaycush in northeastern Lake Michigan, we analyzed stomach contents of Lake Trout caught during gillnet surveys and fishing tournaments from May through October 2016. We then compared the composition, on a wet weight basis, of 2016 diets to those previously described in a recent survey conducted in 2011 . Overall, we found that Lake Trout diets in 2016 consisted mostly (94\% by wet weight) of Alewife and Round Goby Neogobius melanstomus. Averaging across May through October, $61 \%$ of the Lake Trout diet consisted of Alewife. A clear seasonal shift was apparent: the diet was dominated by Round Goby (67\%) during May-June, whereas Alewife dominated the diet (76\%) during July-October. Seasonal dominance of Round Goby in spring Lake Trout diets has not been previously observed in northeastern Lake Michigan, as Round Goby represented only $21 \%$ of the Lake Trout diet in spring of 2011. Diet composition of Lake Trout caught in gill nets did not significantly differ from diet composition of Lake Trout caught by anglers in either the May-June period or the July-October period. Although Lake Trout showed increased diet flexibility in 2016 compared with 2011, Alewife was still the predominant diet component during 2016, despite reduced Alewife biomass throughout Lake Michigan. Nonetheless, this further evidence of diet plasticity suggests Lake Trout may be resilient to ongoing and future forage base changes.

Lake Trout Salvelinus namaycush was the native apex predator of the Lake Michigan food web, and supported a large commercial fishery until populations were extirpated by the 1950s (Eschmeyer 1957; Wells and McLain 1973; Holey et al. 1995). These declines were attributed to overfishing and predation from invasive Sea Lamprey Petromyzon marinus (Eschmeyer 1957; Wells and McClain 1973; Hansen 1999). Extirpation of the piscivorous Lake Trout triggered a proliferation of invasive Alewife Alosa pseudoharengus that reached peak abundance in 1966 (Brown 1972; Madenjian et al. 2005; Collingsworth et al. 2014). Rapid increases in Alewife biomass eventually led to massive die-offs of the Alewife population, creating a serious nuisance and health concern to people who used the lake as a water supply or for recreation (Brown 1972; Hatch et al. 1981). A large-scale salmonine stocking program was 
launched in 1965 to control the nuisance Alewife population, establish an economically valuable recreational fishery, and rehabilitate the Lake Trout population (Tody and Tanner 1966; Holey et al. 1995; Madenjian et al. 2002). In addition to Lake Trout, nonnative Chinook Salmon Oncorhynchus tshawytscha, Coho Salmon O. kisutch, Rainbow Trout O. mykiss, and Brown Trout Salmo trutta were also stocked into Lake Michigan (Tody and Tanner 1966; Eshenroder et al. 1995). This stocking program, in conjunction with concurrent sea lamprey and harvest control efforts (Smith and Tibbles 1980; Bronte et al. 2008), has largely succeeded in increasing Lake Trout populations throughout Lake Michigan - albeit not to pre-1950 levels - and establishing an important recreational fishery for both Lake Trout and nonnative salmonine predators (Tsehaye et al. 2014a, 2014b; Clark et al. 2017; Madenjian et al. 2002). Though the prey fish community in the lake has undergone drastic changes over the last fifty years (Madenjian et al. 2015, 2018), this stocking program remains an important component of lake management.

Alewife populations have been successfully controlled throughout Lake Michigan, but densities are now so low that managers are concerned about forage supply for the salmonine sport fishery. Alewife has long been the dominant prey for salmonine predators in Lake Michigan (Jude et al. 1987; Madenjian et al. 1998), but biomass of adult Alewife was greatly reduced by 1983 and reached historic lows in the 2010s (Madenjian et al. 2002; Collingsworth et al. 2014; Madenjian et al. 2018). As a result, fishery managers were concerned that salmonine consumption of Alewife could not be sustained (Stewart and Ibarra 1991), especially after bacterial kidney disease caused mortality in the Chinook Salmon population from 1986 through the early 2000s (Holey et al. 1998; Benjamin and Bence 2003; Tsehaye et al. 2014b). Managers began to estimate annual consumption of Alewife by salmonines in order to adjust salmonine stocking rates to avoid creating a predator-prey imbalance (Stewart et al. 1981; Stewart and Ibarra 1991; Tsehaye et al. 2014a). Chinook Salmon has been the primary consumer of Alewives in Lake Michigan since 1975 (Tsehaye et al. 2014a; Madenjian et al. 2015). Chinook Salmon stocking rates were first reduced in the 1980s (Hansen et al. 1993), and additional cuts were made during the 1990s, 2000s, and 2010s (Lake Michigan Committee 2014; Tsehaye et al. 2014b). As a result, total consumption of Alewife in Lake Michigan has recently trended downward, but other predators now contribute a greater proportion to the total consumption. In light of record low densities of Alewives combined with increases in abundances of Lake Trout, Rainbow Trout, and Coho Salmon since 2010 (Madenjian et al. 2017, 2018; Kao et al. 2018), 
concern regarding the impact of predation on residual Alewife across Lake Michigan has increasingly focused on non-Chinook salmon predators, as have discussions on further salmonine stocking reductions.

\section{Effective management of the Lake Michigan ecosystem requires a balance between} maintaining nonnative prey species at low levels, while sustaining the popular and economically important recreational fishery and the effort to rehabilitate native Lake Trout populations (Dettmers et al. 2012; Tsehaye et al. 2014b). Continued stocking of Lake Trout is needed in certain regions, such as the Northern Refuge in northeastern Lake Michigan, due to a lack of detectable natural reproduction (Bronte et al. 2008; Madenjian et al. 2017). Currently, stocking rates and salmonine fisheries management in Lake Michigan are guided by the multispecies predator-prey model developed by Tsehaye et al. (2014a) (Lake Michigan Committee 2014). This simulation model combines bioenergetics models with statistical catch-at-age models for salmonines to estimate their annual consumption of Alewife. The current simulation model does not include Round Goby as a potential diet item despite evidence of its increased importance as forage for some salmonines (e.g., Kornis et al. 2012; Roseman et al. 2014; Happel et al. 2018), prompting the need for updated diet information. Additionally, Alewife population size is also tracked using a statistical age-structured population model, which assesses the trade-off between predatory demand and prey productivity. The model is updated every year using the latest data, and if the predator-to-prey biomass ratio is considered to be too high $(>0.10$ based on the value for Lake Huron immediately prior to the Alewife collapse in that lake), fishery managers would consider a stocking reduction of salmonines to maintain a balanced pelagic community.

Despite the importance of the Tsehaye et al. (2014a) predator-prey model to fishery management, the most recent published information on Lake Trout diet in Lake Michigan is from 2011 (Happel et al. 2018). Moreover, the seasonal diet schedule currently used as a model input has not been updated in over 20 years (Madenjian et al. 1998). Seasonal diet schedule refers to a table of diet composition across seasons. Although diet studies have been conducted on Lake Trout since 1994-1995, all have only focused on a specific time of year. An updated seasonal schedule is needed for managers to properly manage the salmonine fishery. With decreasing abundance of Alewife, there is growing uncertainty in the lakewide predatory demand on Alewife and other prey by the combined consumption by all predators. Rainbow Smelt Osmerus mordax, Bloater Coregonus hoyi, and Slimy Sculpin Cottus cognatus have also 
declined in abundance since the 1980s (Madenjian et al. 2018), while Round Goby Neogobius melanostomus biomass rapidly increased during 2000-2010 (Madenjian et al. 2018). Updated information on Lake Trout diets will allow for more realistic predator-prey model results and better-informed management of Lake Michigan fisheries.

Alewife has been the predominant prey of salmonines in Lake Michigan since the 1970s (Stewart and Ibarra 1991; Madenjian et al. 1998; Warner et al. 2008; Happel et al. 2018), representing over $80 \%$ of the diet, on a wet weight basis, of Lake Trout $\geq 400 \mathrm{~mm}$ in total length (TL) during the 1970s (Stewart et al. 1983; Jude et al. 1987). The last published study of Lake Trout diet in Lake Michigan conducted throughout the growing season (April through November) was during 1994-1995 (Madenjian et al. 1998). Although seasonal consumption patterns varied widely between locations, Alewife represented between 55 and $60 \%$ of the diet of Lake Trout in the 400-599 mm TL size range and roughly $65 \%$ of the diet of Lake Trout $\geq 600$ $\mathrm{mm}$ TL when averaged over all seasons and locations. More recent diet studies have been conducted in Lake Michigan but have only focused on spring (April - June) sampling (Jacobs et al. 2010; Happel et al. 2018). The most recent study in northeastern Lake Michigan showed Alewife to be the primary contributor to Lake Trout diets in 2011, with Round Goby comprising roughly one quarter of their diet (Happel et al. 2018). In Lake Huron, Lake Trout shifted their diet to more abundant Rainbow Smelt and Round Goby after the Alewife population completely collapsed in 2003 (O’Gorman et al. 2012; Roseman et al. 2014). In Lake Michigan, adult Lake Trout have previously been shown to select large Alewife, even when other potential prey species are more abundant (Eck and Brown 1985; Eck and Wells 1986; Madenjian et al. 1998), although these studies were conducted prior to the Round Goby population becoming well established in the lake. It is unknown whether the continued decline in Alewife abundance in Lake Michigan has resulted in Lake Trout having a greater reliance on other forage since 2011. The primary objective of our study was to develop an updated diet schedule for Lake Trout from northeastern Lake Michigan that could be used as a bellwether of lakewide diet changes since 2011. A secondary objective was to characterize diets seasonally. We analyzed stomach contents of Lake Trout caught in northeastern Lake Michigan from May through October 2016. In addition, we compared our findings for May 2016 with those of Happel et al. (2018) for Lake Trout caught in northeastern Lake Michigan during spring 2011. Considering results from previous studies, we hypothesized that Alewife would remain the dominant prey of 
Lake Trout from Lake Michigan in 2016, but that Round Goby would be consumed in greater quantities in 2016 compared to 2011.

\section{METHODS}

Field sampling.-Lake Trout were collected throughout northeastern Lake Michigan from May through October 2016 using two sampling methods (Table 1). Fish collections in May and October were part of annual bottom-set gillnet surveys conducted by the U. S. Geological Survey, Great Lakes Science Center (GLSC) within and near the Northern Refuge. In May, fish were captured at Fisherman's Island, Boulder Reef, North Fox Island, and Irishman's Ground (Figure 1). At each site, six sets of two gill nets joined lengthwise were deployed. Each gill net consisted of eight $1.8 \times 30.5 \mathrm{~m}$ panels, with mesh sizes ranging from 6.4 to $15.3 \mathrm{~cm}$ stretched measure in $1.3 \mathrm{~cm}$ increments, according to the Lake Michigan lakewide assessment plan (LWAP) protocol (Schneeberger et al. 1998). At each site, two gillnet sets were within each of the following three depth strata: $15-30 \mathrm{~m}, 31-45 \mathrm{~m}$, and 46-60 m, based on the stratified random sampling protocol of the LWAP. The October survey, targeting spawning aggregations, was conducted at Boulder Reef, North Fox Island, and Gull Island Reef (Figure 1). At each site, 2 sets of two gill nets joined lengthwise were deployed, with each gill net consisting of four 30.5$\mathrm{m}$ panels with mesh sizes of 11.4, 12.7, 14.0, and $15.2 \mathrm{~cm}$ stretched measure (Madenjian and Desorcie 2010). These gill nets were typically set in shallow areas on or near the top of each reef to target spawning fish, and depths ranged from 6.6 to $13.4 \mathrm{~m}$. All set gill nets were deployed for approximately 24 hours prior to retrieval. Captured fish were removed from the net, weighed to the nearest gram, and measured to the nearest millimeter for total length. The gastrointestinal tract from the esophagus to the anus was removed and frozen for later analysis. All Lake Trout used in this study were handled in accordance with guidelines of the American Fisheries Society (2004).

Fish collected during June-August were caught by anglers at fishing tournaments throughout northeastern Lake Michigan. June and August tournaments were located in both Charlevoix and Frankfort, while the July tournament took place in Manistique. At all tournaments, U. S. Fish and Wildlife Service technicians from the Great Lakes mass marking 
program collected gastrointestinal tracts of Lake Trout from anglers returning from fishing trips, in addition to determining total length and weight for each Lake Trout (Bronte et al. 2012).

Stomach content analysis.-We followed the protocol by Elliott et al. (1996) in our analysis of Lake Trout stomach contents. In the laboratory, each stomach was thawed and dissected, then all prey items were visually identified to species when possible, using residual bony structures when necessary (Elliott et al. 1996; Traynor et al. 2010). All prey items, regardless of stage of digestion, were measured to the nearest millimeter (standard length and total length, when possible) and weighed to the nearest 0.1 gram (wet weight). Unidentifiable prey items were also weighed to the nearest 0.1 gram. For Alewife and Round Goby, completely intact individuals were used to develop linear regressions to convert standard length (SL) to total length (TL). The calculated linear regressions were:

$$
\mathrm{TL}=1.23 * \mathrm{SL}-2.4\left(\mathrm{~N}=320 ; \mathrm{r}^{2}=0.976\right) \text { for Alewife; }
$$

$$
\mathrm{TL}=1.21 * \mathrm{SL}-2.6\left(\mathrm{~N}=356 ; \mathrm{r}^{2}=0.980\right) \text { for Round Goby }
$$

Not enough intact individuals were found during our study for all other prey fish, so published regressions (Van Oosten and Deason 1938; Elliott et al. 1996; Jacobs et al. 2010) were used to estimate total length from partially digested prey items. Total lengths were then used to reconstruct the original wet weight of each prey item using published length-weight regression equations (Piccolo et al. 1993; Elliott et al. 1996; Dietrich et al. 2006). Reconstructed prey weights were used for all statistical analyses involving prey biomass.

We generated TL frequency distributions for both Alewife and Round Goby found in the Lake Trout stomachs, using actual and reconstructed total lengths of individual prey items. For each prey fish species, a TL frequency distribution was generated for both the May-June period and the July-October period. All TL frequency distributions were constructed using 10-mm TL bins.

Invertebrate prey were identified to taxonomic order, counted and weighed en masse to the nearest $0.1 \mathrm{~g}$. Adult dipterans and terrestrial adult lepidopterans comprised less than $0.1 \%$ of the total prey weight and were considered in trace amounts and removed from further analysis. Dreissenid mussels were occasionally found in stomachs but were likely either consumed incidentally or were assumed to be prey of other fish, particularly Round Goby (Barton et al. 2005), and omitted from further analysis. Only identifiable prey items were included in the statistical analyses of the diet data. 
Statistical analyses.-To summarize Lake Trout stomach content data, total prey biomass and total number of prey in a stomach were summed across all stomachs pooled together within each sampling month. Then, for each month, per capita total prey biomass and per capita frequency of occurrence of prey were calculated by dividing the sum of total prey biomass and the sum of total number of prey, respectively, by number of Lake Trout with a non-empty stomach sampled during the month. For each combination of prey species and month, we also calculated per capita prey biomass by dividing the total amount of biomass of the prey type consumed by all of the Lake Trout sampled during the month by the corresponding number of Lake Trout with a non-empty stomach. An analogous calculation was used to determine per capita frequency of occurrence for each prey species, by month. Percent contribution of each prey species to per capita total prey biomass and to per capita frequency of occurrence of prey were then computed for each month.

We used analysis of similarities (ANOSIM) to test for differences in the diet composition of Lake Trout between different Lake Trout size categories, sampling methods, and sampling months. ANOSIM is a multivariate analog of analysis of variance and was originally used to assess differences in species abundances among biological communities. Here, we tested for differences in diet compositions between groupings of Lake Trout. This analysis involves a nonparametric permutation to a Bray-Curtis rank dissimilarity matrix (Clarke and Green 1988; Clarke and Warwick 2001). For each Lake Trout with a non-empty stomach, we calculated the percent contribution of each prey species to total prey biomass for that Lake Trout, thereby determining the diet composition for each lake trout. ANOSIM was applied to these diet composition data for Lake Trout individuals. Dissimilarity matrices were constructed by quantifying the compositional dissimilarity index between the diet compositions of individual Lake Trout $\left(\mathrm{BC}_{\mathrm{ij}}\right)$, which is expressed sensu Bray and Curtis (1957) as:

$$
\mathrm{BC}_{\mathrm{ij}}=\frac{1-2 \mathrm{C}_{\mathrm{ij}}}{\mathrm{S}_{\mathrm{i}}+\mathrm{S}_{\mathrm{j}}}
$$

where $\mathrm{C}_{\mathrm{ij}}$ is the sum of only the lesser counts for each of the species found in both stomach samples, and $S_{i}$ and $S_{j}$ are the total number of specimens counted within each respective stomach, with $\mathrm{i}$ and $\mathrm{j}$ indicating different individual Lake Trout. Diet composition data for each Lake Trout was square-root transformed to reduce the importance of dominant prey species (Clarke and Warwick 2001). In addition to generating a $\mathrm{p}$ value to indicate significance of 
differences between tested groups, ANOSIM generates an R value indicating the degree of separation between these groupings. $\mathrm{R}$ values close to 0 indicate indistinguishable groups, $\mathrm{R}$ values $<0.25$ indicate little separation between groups and a high amount of overlap, $R$ values of 0.50 to 0.75 indicate some separation between groups and less overlap, and $\mathrm{R}$ values $>0.75$ indicate clear separation between groups with little overlap (Clarke and Gorley 2001). Lake Trout were grouped into the following size categories: 200-399 mm TL, 400-599 mm TL, 600$799 \mathrm{~mm} \mathrm{TL}$, and TL $\geq 800 \mathrm{~mm}$, as recommended by Elliott et al. (1996), and then ANOSIM was used to determine whether diet composition varied significantly among size categories. If results from the ANOSIM application indicated that size category did not have a significant effect on diet composition, we pooled sizes in all other ANOSIM applications.

To detect a significant diet shift since 2011, we also used ANOSIM to compare diet composition of Lake Trout caught in May 2011 with that in May 2016. The May 2011 data were taken from Happel (2018). Lake Trout in both years were captured using gill nets, and procedures to determine diet composition were consistent across both sampling years.

We identified the prey species that were most important in defining observed differences between diet compositions among groupings of Lake Trout of different size categories, sampling methods, or months of collection by following ANOSIM procedures with a similarity percentage (SIMPER) analysis. SIMPER analysis uses the Bray-Curtis dissimilarity index to compare differences among the proportional mass of each prey species consumed by each grouping of Lake Trout. Both ANOSIM and SIMPER were performed using the vegan package (Oksanen et al. 2017) in Program R version 3.3.2 (R Core Team 2014). All non-empty stomachs were included in these analyses.

A diet schedule for Lake Trout $\geq 400 \mathrm{~mm}$ in TL was constructed by averaging diet composition across individual Lake Trout within each of two seasons: the May-June season and the July-October season. Seasons were defined based on our preliminary examination of the diet composition results. Prey categories included Alewife, Round Goby, Lake Trout, Rainbow Smelt, and other species, based on importance of these species in this study and in previous diet studies (Stewart and Ibarra 1991; Happel et al. 2018). The "other species" category included Slimy Sculpin, Ninespine Stickleback Pungitius pungitius, and Bloater. Alewife were further divided into small ( $\leq 120 \mathrm{~mm}$ TL) and large ( $>120 \mathrm{~mm}$ TL) fish, based on the recommendation by Stewart et al. (1981, 1983). To calculate diet proportions over the entire May-October period, 
we computed the weighted average of the percentage for each of the diet categories between the two seasons, weighting each season by the number of months in that season.

\section{RESULTS}

A total of 496 Lake Trout stomachs were collected from northeastern Lake Michigan, with 342 collected using gill nets and 154 by anglers (Table 1). Mean TL of all collected Lake Trout was $629 \pm 69 \mathrm{~mm}$, while TLs ranged from 373 to $881 \mathrm{~mm}$. Numbers of Lake Trout in the 200-399 mm TL, 400-599 mm TL, 600-799 mm TL, and TL $\geq 800 \mathrm{~mm}$ categories were 1, 158, 328, and 9, respectively. The only Lake Trout less than $400 \mathrm{~mm}$ in TL was angler-caught in August and its stomach did not contain any food. Of the 158 Lake Trout in the 400-599 mm TL category, only 18 Lake Trout were less than $500 \mathrm{~mm}$ in TL. Thus, over 95\% of the Lake Trout used in our study were $\geq 500 \mathrm{~mm}$ in TL. From the 309 stomachs containing food, 2949 individual prey items were found, of which 2737 (93\%) were conclusively identified, accounting for $99 \%$ of the total raw prey weight. Stomachs collected earlier in the year were less likely to be empty, as $86 \%$ of stomachs collected during May-June contained food items compared with only $28 \%$ of stomachs collected during July-October. An average of 5.5 prey items was found in each stomach, with non-empty stomachs containing an average of 8.9 prey items. A higher number of prey items were found in the non-empty stomachs collected earlier in the year than stomachs collected later in the year (10.8 and 2.2 prey items, respectively). Numbers (and percentages) of Lake Trout with a non-empty stomach in the 400-599 mm TL, 600-799 mm TL, and TL $\geq 800$ mm categories were $122(77 \%), 182(55 \%)$, and $5(56 \%)$, respectively.

The two most commonly found prey in the Lake Trout stomachs were Alewife and Round Goby (Table 2). Rainbow Smelt, Slimy Sculpin, Bloater, and Ninespine Stickleback were also found in the Lake Trout stomachs, but the total number of individuals of these prey fish species recovered from the stomachs was only about $2 \%$ of that for Alewife and Round Goby. Several instances of cannibalism were observed, with a total of 15 Lake Trout ranging from 95 to $185 \mathrm{~mm}$ found in 6 stomachs. Invertebrate prey of the taxonomic Orders Diptera and Lepidoptera were found in small quantities in 3 stomachs. All of these insects were adults, and the lepidopterans were terrestrial. 
Alewife and Round Goby were the most important prey items in the May-June period, with Round Goby being the dominant prey species (Table 2). However, this dramatically changed in the July-October period, when Alewife became the dominant prey species and Round Goby occurrence declined; Round Gobies were found in only 17\% of the non-empty stomachs from the July-October period. Along with Alewife, Rainbow Smelt presence in Lake Trout diets increased from the early months to the later months, increasing from $1 \%$ to $4 \%$ of the total prey biomass. These temporal trends were consistent regardless of sampling method. All other species were far less abundant, with each occurring in only a small fraction of diet samples throughout the year. None of these other species accounted for more than $3 \%$ of the total prey biomass.

Over 99\% of the Alewives found in Lake Trout stomachs during May-June were small ( $\leq$ $120 \mathrm{~mm}$ TL), whereas both small and large Alewives were commonly observed in Lake Trout stomachs during July-October (Figure 2). In contrast, most of the Round Gobies eaten by Lake Trout were less than $100 \mathrm{~mm}$ in TL in both the May-June and July-October periods. Modal TL of Alewives found in Lake Trout stomachs increased from $65 \mathrm{~mm}$ in May-June to $155 \mathrm{~mm}$ in JulyOctober, while modal TL of Round Gobies increased just slightly from $75 \mathrm{~mm}$ in May-June to $85 \mathrm{~mm}$ in July-October (Figure 2).

We did not find a statistically significant difference in diet composition between smaller (400-599 mm TL) Lake Trout and larger (600-799 mm TL) Lake Trout (ANOSIM: $\mathrm{p}=0.430$ ). Thus, Lake Trout from the 400-599 mm TL and 600-799 $\mathrm{mm}$ TL categories were pooled in all other analyses. No non-empty stomachs were found in Lake Trout measuring under $400 \mathrm{~mm}$ in TL, while only 5 Lake Trout $\geq 800 \mathrm{~mm}$ in TL had non-empty stomachs. Due to low sample sizes of fish from these two size categories, these fish were excluded from all ANOSIM and SIMPER applications. ANOSIM results also showed that diet composition of Lake Trout captured in May by gill nets did not significantly differ from that of Lake Trout captured in June by anglers ( $\mathrm{p}=$ 0.972). Likewise, there was no significant difference between the diet composition of Lake Trout captured by anglers in July and August and that of Lake Trout captured by gill nets in October $(p=0.690)$. Thus, our presentation of the diet composition results in two groupings, namely the May-June grouping and the July-October grouping, was justified by our ANOSIM results. Moreover, these results suggest that sampling method effects were minimal. Diet composition of Lake Trout significantly differed between the May-June period and the July-October period (ANOSIM, $\mathrm{p}=0.001$ ). In the May-June period, Alewife and Round 
Goby represented $31 \%$ and $67 \%$, respectively, of Lake Trout diet, on a wet weight basis (Table 3). In stark contrast, Alewife and Round Goby represented $76 \%$ and $14 \%$, respectively, of Lake Trout diet during the July-October period (Table 3). The diet overlap index (generated from the ANOSIM run) between the May-June and July-October periods was moderately high ( $\mathrm{R}$ value $=$ 0.30). As mentioned above, diet composition of gillnet-caught Lake Trout did not significantly differ from diet composition of angler-caught Lake Trout in either the May-June period or the July-October period. Diet overlap between the two gear was very high $(\mathrm{R}$ value $<0.10)$ for both periods. The differences in diet compositions between groupings of Lake Trout were largely driven by differences in the percentages of Alewife and Round Goby, as these two species contributed more than $88 \%$ of the dissimilarity between diet compositions for all comparisons.

In May 2016, Lake Trout diet composition in northeastern Lake Michigan was dominated by Round Goby (65\%). In contrast, Lake Trout consumed far more Alewife (62\%) than Round Goby (21\%) during the spring of 2011. Although there was a significant difference in diet composition between the two years (ANOSIM, $\mathrm{p}=0.001$ ), diet overlap was still substantial between years $(\mathrm{R}$ value $=0.24)$.

Over the May-October period, Alewife was the dominant prey item and accounted for $61 \%$ of the identified prey biomass, while Round Goby accounted for $32 \%$ of the identified prey biomass (Table 3). Although Round Goby has become increasingly important in the spring diet, Alewife is still the most important prey species for Lake Trout in northeastern Lake Michigan over the May-October period (Table 3). Large Alewife was a minor component of Lake Trout diet during the May-June period, but was the most important diet component during the JulyOctober period. Over the May-October period, the contribution of large Alewife to Lake Trout $\operatorname{diet}(31 \%)$ was just slightly higher than the contribution of small Alewife to Lake Trout diet (30\%) (Table 3). In our study, all 5 of the Lake Trout over $800 \mathrm{~mm}$ in TL with a non-empty stomach were caught by anglers in August. These fish fed exclusively on large (> $120 \mathrm{~mm}$ TL) Alewife.

\section{DISCUSSION}

As we hypothesized, Alewife was the dominant prey species of Lake Trout $\geq 400 \mathrm{~mm}$ in TL in northeastern Lake Michigan in 2016, while Round Goby has become more important in 
Lake Trout diet since 2011. We estimated that Alewife represented $61 \%$ of the diet of Lake Trout over the course of our sampling period, which spanned from spring to fall. This suggests that the importance of Alewife in the diets Lake Trout over this spring-to-fall period has not significantly changed in Lake Michigan since the last spring-to-fall study conducted in 19941995, when Alewife represented between 55 and 65\% of prey consumed (Madenjian et al. 1998). However, the composition of the other $\sim 40 \%$ of Lake Trout diets has changed substantially. Bloater, Rainbow Smelt, and Sculpin spp. comprised much of the non-Alewife diet in 19941995, which was after the initial discovery of Round Goby in Lake Michigan but prior to its proliferation (Kornis et al. 2012). By contrast, Round Goby accounted for approximately 32\% of the Lake Trout diet over the May-October period in 2016, while contributions of Rainbow Smelt, Bloater and Sculpin combined for only $5 \%$ of the diet composition by weight over this same period. Contrary to 1994-1995, Lake Trout consumption in 2016 consisted almost exclusively of Alewife and Round Goby.

We found a strong seasonal effect whereby Round Goby was the dominant prey species in spring (67\% of diet by weight), while Alewife contributed an overwhelming portion of food consumed by Lake Trout in summer and fall ( $76 \%$ of diet by weight). Our study represented the first documentation ever of this drastic seasonal shift in Lake Trout diet composition in Lake Michigan. The most recent published diet study in northeastern Lake Michigan in spring of 2011 showed that Alewife was still the most important prey (62\% of the diet) and Round Goby was of relatively low importance (21\% of diet; Happel et al. 2018).

The diet shift from Round Goby in spring to Alewife in summer and fall did not appear to be an artifact of the collection method. In other words, gear appeared to have little effect on Lake Trout diet composition. Similarly, Jacobs et al. (2013) concluded that there was little difference in diet composition between Chinook Salmon caught by anglers and those caught with suspended gill nets. However, even greater differences in diet composition of gillnet-caught Lake Trout versus angler-caught Lake Trout were anticipated because bottom gill nets were thought to be more likely to catch fish feeding on bottom, where Round Goby are prevalent, while anglers often troll through the water column where Alewife are prevalent. This lack of a sampling method effect is an important finding for fisheries managers who have questioned whether observations of more Round Goby in Lake Trout diet in spring compared with summer was a result of a difference in prevailing sampling methods (gill nets in spring, angling in summer). 
Gill nets used in May included smaller mesh sizes than those used in October spawner surveys, so May sampling was more likely to capture smaller Lake Trout. Predictably, May sampling captured Lake Trout with a wider length range than in October, with more fish caught in the 400-599 mm TL range. While Lake Trout caught in May were, on the average, smaller than those caught in October, the difference was not statistically significant. Despite differences in size distribution of Lake Trout captured between these two sampling methods, we did not find Lake Trout TL to be a good predictor of diet composition, and we concluded that use of different gill nets in May and October did not influence our results. Moreover, these findings further support our conclusion that changes in diet composition were the result of seasonality and not gear selectivity.

The seasonal shift from Round Goby to Alewife is likely a result of a difference in the seasonal depth distributions between these two prey fish species, as well as a seasonal shift in the vertical movements of Lake Trout. In the spring of some years, the bulk of the mature Alewife population inhabits waters deeper than $70 \mathrm{~m}$ (O'Gorman et al. 2000), which is considerably deeper than the waters where Lake Trout were captured for our study. Mature Alewife make spawning migrations towards shore during spring and spawn in shallow waters during the late spring and summer (Wells 1968; Brown 1972; O'Gorman et al. 2000). Peak spawning occurs during early summer, though some spawning continues through early August. Individual Alewives spawn just once each year, and then move to deeper water soon after spawning. Lake Trout are generally found in colder and deeper water, especially during the summer, meaning they do not overlap with spawning Alewives (Eck and Wells 1986). However, since adult Alewife do not all spawn at the same time of year, there is always a portion of the adult Alewife population spatially overlapping with Lake Trout throughout summer and fall. Round Goby similarly move from deeper water to shallow habitats during their spawning season, which can start as early as April but largely occurs from June to September (Kornis et al. 2012). In contrast to Alewife, Round Goby spawn multiple times each year and largely remain in shallow water into early autumn before migrating back to deeper water to overwinter (Charlebois et al. 1997; Walsh et al. 2007). Round Goby spawning mostly occurs in relatively shallow nearshore areas less than $15 \mathrm{~m}$ deep, although some spawning at greater depths has been observed (Corkum et al. 1998; Johnson et al. 2005; Taraborelli et al. 2009; Kornis et al. 2012). With Lake Trout inhabiting deeper, colder water, they do not overlap with the bulk of the Round Goby population 
during summer and early fall (Dahlberg 1981; Eck and Wells 1986; Kornis et al. 2012). However, during the May-June period, Lake Trout spatially overlap with Round Goby as Round Goby migrate from deep to shallow water. During the summer and fall, a substantial portion of the adult Alewife population spatially overlaps with the Lake Trout population in Lake Michigan while most Round Goby are in shallow nearshore waters, explaining the dominance of adult Alewife in Lake Trout diet during this time. In addition to species-specific differences in seasonal depth distributions of prey fish, a seasonal shift in vertical movements of Lake Trout also likely contributed to the observed seasonal change in Lake Trout diet composition. Results from recent telemetry studies have indicated that Lake Trout tend to be primarily demersal in the spring, but then become more pelagic, with increased vertical movements, during the summer and fall (Guzzo et al. 2017; Gallagher et al. 2019). Because Alewife is a more pelagic prey than Round Goby, availability of Alewife to Lake Trout would be expected to increase from spring to summer and fall.

Round Goby has become significantly more important in the spring diet of Lake Trout from northeastern Lake Michigan over the past 10 years. Round Goby accounted for $<2 \%$ of spring diet by weight in Lake Trout during 2006-2008 (Jacobs et al. 2010). This percentage increased to $21 \%$ of prey biomass by 2011 (Happel et al. 2018), and then to 67\% by 2016. In southeastern Lake Michigan, Round Goby had become important in the spring diet of Lake Trout by 2011 , when this prey species represented $49 \%$ of the diet composition (Happel et al. 2018). Perhaps availability of Alewives in the spring declined at a faster rate in southeastern Lake Michigan than in northeastern Lake Michigan, triggering Lake Trout to change their feeding behavior there first. Reduced abundance of all pelagic forage may make feeding more energetically efficient in benthic habitats, where Round Goby are more abundant, instead of pelagic habitats previously inhabited by higher densities of Alewife, Bloater, and Rainbow Smelt (Wells 1968; Charlebois 1997; Tsehaye et al. 2014a). This diet shift from Alewife to Round Goby in spring resembles findings in Lake Ontario and Lake Huron, where Round Goby became a more important component of Lake Trout diets as the abundances of Alewife and Rainbow Smelt declined (Rush et al. 2012; He et al. 2015; Roseman et al. 2014). Continued declines in Alewife biomass may cause further shifts to consumption of Round Goby.

We considered the possibility that the increased importance of Round Goby in Lake Trout diets during May and June could be explained by an expanding range or an increasing 
Round Goby population abundance since 2011. However, this is unlikely, as Round Goby was found in the Northern Refuge as early as 2007 (Jacobs et al. 2010), and recent prey fish surveys indicate that their biomass has leveled off or even decreased since the early 2010s (Madenjian et al. 2018), suggesting that increased consumption of Round Goby was not linked to increases in Round Goby abundance. Instead, it appears that Round Goby spatially overlapped with Lake Trout prior to 2016, but may not have immediately become important forage due to the time lag generally observed in predators exposed to novel prey (Pothoven and Madenjian 2013). In addition, Lake Trout have been shown to forage on Alewife at a disproportionately high level relative to Alewife ambient abundance, even when alternative prey species are also abundant (Eck and Wells 1986; He et al. 2015). For example, Round Goby did not become an important diet component of Lake Trout in Lake Huron until the Alewife population completely collapsed in the early 2000s (Riley et al. 2008; He et al. 2015). The significant change in feeding behavior further suggests that Lake Trout in Lake Michigan could be more responsive to declines of preferred prey than to increases in abundance of alternative prey species.

Size of Alewives consumed by Lake Trout in Lake Michigan during 2016 was less than that during 1994-1995. In 1994-1995, modal TLs of small and large Alewives consumed by Lake Trout were $75 \mathrm{~mm}$ and $175 \mathrm{~mm}$, respectively (Madenjian et al. 1998). In 2016, modal TLs of small and large Alewives consumed by Lake Trout were $65 \mathrm{~mm}$ and $155 \mathrm{~mm}$, respectively. This shift to consumption of smaller Alewife was expected as annual bottom trawl surveys indicated that Alewives have decreased in both abundance and size (Madenjian et al. 2006, 2015, 2018). Jacobs et al.(2013) documented a similar decline in the size of Alewives consumed by Chinook Salmon in Lake Michigan between 1994 and 2010.

A comparison of Lake Trout diet composition in Lake Superior with that in Lakes Michigan, Huron, and Ontario suggests that Alewives form the mainstay of adult Lake Trout diet when they are readily available for consumption by Lake Trout. Alewives successfully invaded Lakes Ontario, Huron, and Michigan to become well established in these three lakes, but Alewives never became well established in Lake Superior (O'Gorman et al. 2012). Alewives have dominated the diet of adult Lake Trout in Lake Ontario during the 1980s, 1990s, and 2000s (Madenjian et al. 1995; Rush et al. 2012), and Alewives have been the predominant prey of adult Lake Trout in Lake Michigan since the 1970s. Alewives represented the single most important prey for Lake Trout in Lake Huron during the 1980s and 1990s (He et al. 2015). However, 
following the complete collapse of the Alewife population in Lake Huron during 2002-2004, the importance of Alewives in adult Lake Trout diet was greatly reduced, and the contribution of Alewives to adult Lake Trout diet in recent years has been practically negligible. Alewife in the diet of adult Lake Trout in Lake Huron was mainly replaced by Rainbow Smelt and Round Goby, beginning in 2005 (He et al. 2015). Since the 1980s, adult Lake Trout in Lake Superior have fed on a variety of fish, including coregonines (mainly Cisco Coregonus artedi), Rainbow Smelt, sculpins (mainly Deepwater Sculpin Myoxocephalus thompsonii), Ninespine Stickleback, and Burbot Lota lota (Ray et al. 2007; Gamble et al. 2011a, 2011b).

\section{Management Implications}

Our results will be useful in updating the predator-prey model by Tsehaye et al. (2014a) used to guide salmonine stocking decisions in Lake Michigan. Round Goby consumption has not been considered previously when running this simulation model. Thus, our results could be used to better advise future management of salmonines in Lake Michigan. We observed a substantial increase in the importance of Round Goby in the spring diet of Lake Trout from 2011 to 2016, and it is possible Round Goby has also become increasingly important for other piscivores over this period. A lakewide analysis of Lake Trout and other salmonine diets is ongoing for updating the predator-prey model, but our regional analysis does provide important insights into the shifting diet composition of Lake Trout, as well as into gear effects (or lack thereof) on diet composition of Lake Trout. We were the first to show that the diet of adult Lake Trout in Lake Michigan undergoes a dramatic shift between the spring and summer, whereby Round Goby dominates the spring diet while Alewife dominates the diet during summer and fall months. In addition, our findings indicated that gillnet-caught Lake Trout and angler-caught Lake Trout were similar in their diet composition. Overall, our findings will aid in the sound management of the salmonine communities in Lake Michigan, thereby achieving the goals set out by the Lake Michigan Committee, which operates under the auspices of the Great Lakes Fishery Commission (Eshenroder et al. 1995; Bronte et. 2008; Dexter et al. 2011).

\section{ACKNOWLEDGMENTS}

We thank the following: Austin Happel for providing us with 2011 Lake Trout diet data; Joe Bergan and the crew of the USGS $R / V$ Sturgeon for their assistance collecting fish for this 
study; Dave Bennion (USGS) for the GIS maps; Tim Desorcie (USGS) for assistance with the stomach processing and prey identification; Barrett Warmbein (USFWS) and Brittany Miller (USFWS) for angler stomach collections; and Rob Elliott (USFWS) for reviewing the manuscript. This project was made possible by funding from the Great Lakes Fishery Commission and the Great Lakes Restoration Initiative, as well as from an Edna Bailey Sussman Grant to the lead author from the University of Michigan. Data in this report are available at: U.S. Geological Survey, Great Lakes Science Center, 2019, Great Lakes Research Vessel Operations 1958-2018 (ver. 3.0, April 2019): U.S. Geological Survey Data Release, https://doi.org/10.5066/F75M63X0. The findings and conclusions in this article are those of the authors and do not necessarily represent the views of the U.S. Fish and Wildlife Service. Use of trade, product, or firm names does not imply endorsement by the U.S. Government.

\section{REFERENCES}

American Fisheries Society. 2004. Guidelines for the use of fishes in research. Available online: https://fisheries.org/docs/policy_useoffishes.pdf (December 2018).

Barton, D. R., R. A. Johnson, L. Campbell, J. Petruniak, and M. Patterson. 2005. Effects of round gobies (Neogobius melanostomus) on dreissenid mussels and other invertebrates in eastern Lake Erie, 2002-2004. Journal of Great Lakes Research 31:252-261.

Benjamin, D. M., and J. R. Bence. 2003. Statistical catch-at-age framework for Chinook salmon in Lake Michigan, 1985-1996. Michigan Department of Natural Resources, Fisheries Division, Ann Arbor, Michigan.

Bray, J. R., and J. T. Curtis. 1957. An ordination of the upland forest communities of southern Wisconsin. Ecological Monographs 27:325-349.

Bronte, C. R., C. C. Krueger, M. E. Holey, M. L. Toneys, R. L. Eshenroder, and J. L. Jonas. 2008. A guide for the rehabilitation of Lake Trout in Lake Michigan. Great Lakes Fishery Commission, Miscellaneous Publication 2008-01, Ann Arbor, Michigan.

Bronte, C. R., K. A. Walch, J. M. Dettmers, M. Gaden, M. J. Connerton, M. Daniels, and T. J. Newcomb. 2012. A coordinated mass marking program for salmonines stocked into the Laurentian Great Lakes. American Fisheries Society Symposium.76:27-42.

Brown, E. H, Jr. 1972. Population biology of alewives, Alosa pseudoharengus, in Lake Michigan, 1949-70. Journal of the Fisheries Board of Canada 29:477-500. 
Charlebois, P. M., J. E. Marsden, R. G. Goettel, R. K. Wolfe, D. J. Jude, and S. Rudnicka. 1997. The round goby, Neogobius melanostomus (Pallas): a review of European and North American literature (Vol. 20). Illinois-Indiana Sea Grant Program.

Clark, R. D., Jr., J. R. Bence, R. M. Claramunt, J. A. Clevenger, M. S. Kornis, C. R. Bronte, C. P. Madenjian, and E. F. Roseman. 2017. Changes in movements of Chinook Salmon between Lakes Huron and Michigan after alewife population collapse. North American Journal of Fisheries Management 37:1311-1331.

Clarke, K. R., and R. N. Gorley. 2001. Primer V5 (Plymouth routines in multivariate ecological research): user manual/tutorial. Primer-E.

Clarke, K. R., and R. H. Green. 1988. Statistical design and analysis for a "biological effects" study. Marine Ecology Progress Series 46:213-226.

Clarke, K. R., and R. M. Warwick. 2001. Changes in marine communities: an approach to statistical analyses and interpretation. Primer-E, 2nd edition. Primer-E-LTD, Plymouth, United Kingdom.

Collingsworth, P. D., D. B. Bunnell, C. P. Madenjian, and S. C. Riley. 2014. Comparative recruitment dynamics of alewife and bloater in lakes Michigan and Huron. Transactions of the American Fisheries Society 143:294-309.

Corkum, L.D., A. J. MacInnis, and R. G. Wickett. 1998. Reproductive habits of round gobies. Great Lakes Research Review 3:13-20.

Dahlberg, M. D. 1981. Nearshore spatial distribution of fishes in gill net samples, Cayuga Lake, New York. Journal of Great Lakes Research 7:7-14.

Dettmers, J. M., C. I. Goddard, and K. D. Smith. 2012. Management of alewife using Pacific salmon in the Great Lakes; whether to manage for economics or the ecosystem? Fisheries 37:495-501.

Dexter, J. L., B. T. Eggold, T. K. Gorenflo, W. H. Horns, S. R. Robillard, and S. T. Shipman. 2011. A fisheries management implementation strategy for the rehabilitation of lake trout in Lake Michigan. Great Lakes Fishery Commission, Lake Michigan Committee, Ann Arbor, Michigan.

Dietrich, J. P., A. C. Taraborelli, B. J. Morrison, and T. Schaner. 2006. Allometric relationships between size of calcified structures and round goby total length. North American Journal of Fisheries Management 26:926-931. 
Eck, G. W., and E. H. Brown, Jr. 1985. Lake Michigan's capacity to support lake trout and other salmonines: An estimate based on the status of prey populations in the 1970s. Canadian Journal of Fisheries and Aquatic Sciences 42:449-454.

Eck, G. W., and L. Wells. 1986. Depth distribution, diet, and overwinter growth of lake trout (Salvelinus namaycush) in southeastern Lake Michigan sampled in December 1981 and March 1982. Journal of Great Lakes Research 12:263-269.

Elliott, R. F., P. J. Peeters, M. P. Ebener, R. W. Rybicki, P. J. Schneeberger, R. J. Hess, J. T. Francis, G. W. Eck, and C. P. Madenjian. 1996. Conducting diet studies of Lake Michigan piscivores - a protocol. US Fish and Wildlife Service, Green Bay Fishery Resource Office, Green Bay, Wisconsin.

Eschmeyer, P. H. 1957. The near extinction of lake trout in Lake Michigan. Transactions of the American Fisheries Society 85:102-119.

Eshenroder, R. L., M. E. Holey, T. K. Gorenflo, and R. D. Clark, Jr. 1995. Fish community objectives for Lake Michigan. Great Lakes Fishery Commission, Special Publication 99-1, Ann Arbor, Michigan.

Gallagher, C. P., M. M. Guzzo, and T. A. Dick. 2019. Seasonal depth and temperature use, and diel movements of lake trout (Salvelinus namaycush) in a subarctic lake. Canadian Journal of Fisheries and Aquatic Science 76:in press.

Gamble, A. E., T. R. Hrabik, J. D. Stockwell, and D. L. Yule. 2011a. Trophic connections in Lake Superior Part I: The offshore fish community. Journal of Great Lakes Research $37: 541-549$.

Gamble, A. E., T. R. Hrabik, D. L. Yule, and J. D. Stockwell. 2011b. Trophic connections in Lake Superior Part II: The nearshore fish community. Journal of Great Lakes Research 37:550-560.

Guzzo, M.M., P. J. Blanchfield, and M. D. Rennie. 2017. Behavioral responses to annual temperature variation alter the dominant energy pathway, growth, and condition of a coldwater predator. Proceedings of the National Academy of Sciences of the United States of America 114:9912-9917.

Hansen, M. J. 1999. Lake trout in the Great Lakes: basin-wide stock collapse and binational restoration. Pages 417-453 in W. W. Taylor and C. P. Ferreri, editors. Great Lakes fisheries 
policy and management: A binational perspective, 2nd edition. Michigan State University Press, East Lansing.

Hansen, M. J., D. Boisclair, S. B. Brandt, S. W. Hewett, J. F. Kitchell, M. C. Lucas, and J. J. Ney.1993. Applications of bioenergetics models to fish ecology and management: where do we go from here? Transactions of the American Fisheries Society 122:1019-1030.

Happel, A., J. L. Jonas, P. R. McKenna, J. Rinchard, J. X. He, and S. J. Czesny. 2018. Spatial variability of lake trout diets in Lakes Huron and Michigan revealed by stomach content and fatty acid profiles. Canadian Journal of Fisheries and Aquatic Sciences 75:95-105.

Hatch, R. W., P. M. Haack, and E. H. Brown, Jr. 1981. Estimation of alewife biomass in Lake Michigan, 1967-1978. Transactions of the American Fisheries Society 110:575-584.

He, J. X., J. R. Bence, C. P. Madenjian, S. A. Pothoven, N. E. Dobiesz, D. G. Fielder, J. E. Johnson, M. P. Ebener, R. A. Cottrill, L. C. Mohr, and S. R. Koproski. 2015. Coupling agestructured stock assessment and fish bioenergetics models: a system of time-varying models for quantifying piscivory patterns during the rapid trophic shift in the main basin of Lake Huron. Canadian Journal of Fisheries and Aquatic Sciences 72:7-23.

Holey, M. E., R.F. Elliott, S. V. Marcquenski, J. G. Hnath, and K. D. Smith. 1998. Chinook salmon epizootics in Lake Michigan: possible contributing factors and management implications. Journal of Aquatic Animal Health 10:202-210.

Holey, M. E., R. W. Rybicki, G. W. Eck, E. H. Brown, Jr., J. E. Marsden, D. S. Lavis, M. L. Toneys, T. N. Trudeau, and R. M. Horrall. 1995. Progress toward lake trout restoration in Lake Michigan. Journal of Great Lakes Research 21(Supplement 1):128-151.

Jacobs, G. R., C. P. Madenjian, D. B. Bunnell, and J. D. Holuszko. 2010. Diet of lake trout and burbot in northern Lake Michigan during spring: evidence of trophic interaction. Journal of Great Lakes Research 36:312-317.

Jacobs, G. R., C. P. Madenjian, D. B. Bunnell, D. M. Warner, and R. M. Claramunt. 2013. Chinook salmon foraging patterns in a changing Lake Michigan. Transactions of the American Fisheries Society 142:362-372.

Johnson, T. B., D. B. Bunnell, and C. T. Knight. 2005. A potential new energy pathway in central Lake Erie: the round goby connection. Journal of Great Lakes Research 31(Supplement 2):238-251. 
Jude, D. J., F. J. Tesar, S. F. Deboe, and T. J. Miller. 1987. Diet and selection of major prey species by Lake Michigan salmonines, 1973-1982. Transactions of the American Fisheries Society 116:677-691.

Kao, Y., M. W. Rogers, and D. B. Bunnell. 2018. Evaluating stocking efficacy in an ecosystem undergoing oligotrophication. Ecosystems 21:600-618.

Kornis, M. S., N. Mercado-Silva, and M. J. Vander Zanden. 2012. Twenty years of invasion: a review of round goby Neogobius melanostomus biology, spread and ecological implications. Journal of Fish Biology 80:235-285.

Lake Michigan Committee. 2014. Lake Michigan salmonine stocking strategy. Great Lakes Fishery Commission, Ann Arbor, Michigan. Available: http://www.glfc.org/pubs/lake_committees/michigan/Lake\%20Michigan\%20Committee $\% 2$ 0Salmon\%20Stocking\%20Strategy\%202014.pdf. (October 2017).

Madenjian C., B. Breidert, D. Boyarski, C. Bronte, B. Dickinson, K. Donner, M. Ebener, R. Gordon, D. Hanson, M. Holey, J. Janssen, J. Jonas, M. Kornis, E. Olsen, S. Robillard, T. Treska, B. Weldon, and G. Wright. 2017. 2016 Lake Michigan Lake Trout Working Group report. Presented at the Great Lakes Fishery Commission, Lake Michigan Committee Meeting, Ypsilanti, Michigan, March 20, 2017.

Madenjian, C. P., D. B. Bunnell, T. J. Desorcie, P. Armenio, and J. V. Adams. 2018. Status and trends of prey fish populations in Lake Michigan, 2017. Presented at the Great Lakes Fishery Commission, Lake Michigan Committee, Sault Ste. Marie, Ontario, Canada, March $22,2018$.

Madenjian, C. P., D. B. Bunnell, D. M. Warner, S. A. Pothoven, G. L. Fahnenstiel, T. F. Nalepa, H. A. Vanderploeg, I. Tsehaye, R. M. Claramunt, and R. D. Clark, Jr. 2015. Changes in the Lake Michigan food web following dreissenid mussel invasions: A synthesis. Journal of Great Lakes Research 41(Supplement 3):217-231.

Madenjian, C. P., and T. J. Desorcie. 2010. Lake trout population dynamics in the Northern Refuge of Lake Michigan: implications for future rehabilitation. North American Journal of Fisheries Management 30:629-641.

Madenjian, C. P., T. J. Desorcie, and R. M. Stedman. 1998. Ontogenic and spatial patterns in diet and growth of lake trout in Lake Michigan. Transactions of the American Fisheries Society 127:236-252.

This article is protected by copyright. All rights reserved 
Madenjian, C. P., G. L. Fahnenstiel, T. H. Johengen, T. F. Nalepa, H. A. Vanderploeg, G. W. Fleischer, P. J. Schneeberger, D. M. Benjamin, E. B. Smith, J. R. Bence, E. S. Rutherford, D. S. Lavis, D. M. Robertson, D. J. Jude, and M. P. Ebener. 2002. Dynamics of the Lake Michigan food web, 1970-2000. Canadian Journal of Fisheries and Aquatic Sciences 59:736-753.

Madenjian, C. P., T. O. Höök, E. S. Rutherford, D. M. Mason, T. E. Croley, E. B. Szalai, and J. R. Bence. 2005. Recruitment variability of alewives in Lake Michigan. Transactions of the American Fisheries Society 134:218-230.

Madenjian, C. P., S. A. Pothoven, J. M. Dettmers, and J. D. Holuszko. 2006. Changes in seasonal energy dynamics of alewife (Alosa pseudoharengus) in Lake Michigan after invasion of dreissenid mussels. Canadian Journal of Fisheries and Aquatic Sciences 63:891-902. Madenjian, C. P., D. M. Whittle, J. H. Elrod, R. O’Gorman, and R. W. Owens. 1995. Use of a simulation model to reconstruct PCB concentrations in prey of Lake Ontario lake trout. Environmental Science \& Technology 29:2610-2615.

O’Gorman, R., J.H. Elrod, R. W. Owens, C. P. Schneider, T. H. Eckert, and B. F. Lantry. 2000. Shifts in depth distributions of alewives, rainbow smelt, and age-2 lake trout in southern Lake Ontario following establishment of dreissenids. Transactions of the American Fisheries Society 129:1096-1106.

O’Gorman, R., C. P. Madenjian, E. F. Roseman, A. Cook, and O. T. Gorman. 2012. Alewife in the Great Lakes: old invader-new millennium. Pages 705-732 in W. W. Taylor, A. J. Lynch, and N. J. Leonard, editors. Great Lakes fisheries policy and management: a binational perspective, 2nd edition. Michigan State University Press, East Lansing.

Oksanen, J., F. G. Blanchet, M. Friendly, R. Kindt, P. Legendre, D. McGlinn, P. R. Minchin, R. B. O'Hara, G. L. Simpson, P. Solymos, M. H. H. Stevens, E. Szoecs, and H. Wagner. 2017. vegan: Community Ecology Package. R package version 2.4-2. Available: https://CRAN.R-project.org/package=vegan.

Piccolo, J. J., W. A. Hubert, and R. A. Whaley. 1993. Standard weight equation for lake trout. North American Journal of Fisheries Management 13:401-404.

Pothoven, S. A., and C. P. Madenjian. 2013. Increased piscivory by Lake Whitefish in Lake Huron. North American Journal of Fisheries Management 33:1194-1202. 
R Core Team. 2014. R: A language and environment for statistical computing. R Foundation for Statistical Computing, Vienna, Austria. Available: http://www.R-project.org/.

Ray, B. A., T. R. Hrabik, M. P. Ebener, O. T. Gorman, D. R. Schreiner, S. T. Schram, S. P. Sitar, W. P. Mattes, and C. R. Bronte. 2007. Diet and prey selection by Lake Superior lake trout during spring, 1986-2001. Journal of Great Lakes Research 33:104-113.

Riley, S. C., E. F. Roseman, S. J. Nichols, T. P. O’Brien, C. S. Kiley, and J. S. Schaeffer. 2008. Deepwater demersal fish community collapse in Lake Huron. Transactions of the American Fisheries Society 137:1879-1890.

Roseman, E. F., J. S. Schaeffer, E. Bright, and D. G. Fielder. 2014. Angler-caught piscivore diets reflect fish community changes in Lake Huron. Transactions of the American Fisheries Society 143:1419-1433.

Rush, S. A., G. Paterson, T. B. Johnson, K. G. Drouillard, G. D. Haffner, C. E. Hebert, M. T. Arts, D. J. McGoldrick, S. M., Backus, B. F., Lantry, J. R. Lantry, T. Schaner, and A. T. Fisk. 2012. Long-term impacts of invasive species on a native top predator in a large lake system. Freshwater Biology 57:2342-2355.

Schneeberger, P., M. Toneys, R. Elliott, J. Jonas, D. Clapp, R. Hess, and D. Passino-Reader. 1998. Lakewide assessment plan for Lake Michigan fish communities. Great Lakes Fishery Commission, Lake Michigan Technical Committee, Ann Arbor, Michigan. Available: http://www.glfc.org/pubs/SpecialPubs/lwasses01.pdf. (July 2012).

Smith, B.R., and J. J. Tibbles. 1980. Sea lamprey (Petromyzon marinus) in Lakes Huron, Michigan, and Superior: history of invasion and control, 1936-78. Canadian Journal of Fisheries and Aquatic Sciences 37:1780-1801.

Stewart, D. J., J. F. Kitchell, and L. B. Crowder. 1981. Forage fishes and their salmonid predators in Lake Michigan. Transactions of the American Fisheries Society 110:751-763.

Stewart, D. J., and M. Ibarra. 1991. Predation and production by salmonine fishes in Lake Michigan, 1978-88. Canadian Journal of Fisheries and Aquatic Sciences 48:909-922.

Stewart, D. J., D. Weininger, D. V. Rottiers, and T. A. Edsall. 1983. An energetics model for lake trout, Salvelinus namaycush: application to the Lake Michigan population. Canadian Journal of Fisheries and Aquatic Sciences 40:681-698. 
Taraborelli, A. C., M. G. Fox, T. Schaner, and T. B. Johnson. 2009. Density and habitat use by the round goby (Apollonia melanostoma) in the Bay of Quinte, Lake Ontario. Journal of Great Lakes Research 35:266-271.

Tody, W. H., and H. A. Tanner. 1966. Coho salmon for the Great Lakes. Michigan Department of Natural Resources, Fish Management Report 1, Lansing.

Traynor D., A. Moerke, and R. Greil. 2010. Identification of Michigan fishes using cleithra. Great Lakes Fisheries Commission Miscellaneous Publication 2010-02.

Tsehaye, I., M. L. Jones, J. R. Bence, T. O. Brenden, C. P. Madenjian, and D. M. Warner. $2014 a$. A multispecies statistical age-structured model to assess predator-prey balance: application to an intensively managed Lake Michigan pelagic fish community. Canadian Journal of Fisheries and Aquatic Sciences 71:1-18.

Tsehaye, I., M. L. Jones, T. O. Brenden, J. R. Bence, and R. M. Claramunt. 2014b. Changes in the salmonine community of Lake Michigan and their implications for predator-prey balance. Transactions of the American Fisheries Society 143:420-437.

Van Oosten, J., and H. J. Deason. 1938. The food of the lake trout (Cristivomer namaycush namaycush) and of the lawyer (Lota maculosa) of Lake Michigan. Transactions of the American Fisheries Society 67:155-177.

Walsh, M. G., D. E. Dittman, and R. O'Gorman. 2007. Occurrence and food habits of the round goby in the profundal zone of southwestern Lake Ontario. Journal of Great Lakes Research 33:83-92

Warner, D. M., C. S. Kiley, R. M. Claramunt, and D. F. Clapp. 2008. The influence of alewife year-class strength on prey selection and abundance of age-1 Chinook salmon in Lake Michigan. Transactions of the American Fisheries Society 137:1683-1700.

Wells, L. 1968. Seasonal depth distribution of fish in southeastern Lake Michigan. Fishery Bulletin 67:1-15.

Wells, L., and A. L. McLain. 1973. Lake Michigan: man's effects on native fish stocks and other biota (No. 20, pp. 0-55). Great Lakes Fishery Commission, Technical Report 20, Ann Arbor, Michigan.

TABLE 1. Sampling method used, number of Lake Trout sampled (N), mean Lake Trout total length ( \pm standard error), number of stomachs containing food, percent of non-empty stomachs, and average number of prey items in non-empty stomachs, by month, for Lake Trout caught in 
768 northeastern Lake Michigan during 2016. For the May-June, July-October, and May-October 769 groupings, gillnet-caught and angler-caught Lake Trout were pooled.

\begin{tabular}{lcccccc}
\hline Month & $\begin{array}{c}\text { Sampling } \\
\text { method }\end{array}$ & $\mathrm{N}$ & $\begin{array}{c}\text { Mean total } \\
\text { length }(\mathrm{mm})\end{array}$ & $\begin{array}{c}\text { Non-empty } \\
\text { stomachs }\end{array}$ & $\begin{array}{c}\text { Percent } \\
\text { non-empty }\end{array}$ & $\begin{array}{c}\text { Average } \\
\text { number of prey }\end{array}$ \\
\hline May & Gill net & 221 & $607 \pm 60$ & 210 & 95 & 11.8 \\
June & Angler & 59 & $632 \pm 78$ & 30 & 51 & 3.9 \\
July Angler & 19 & $613 \pm 36$ & 16 & 84 & 2.4 \\
August & Angler & 66 & $627 \pm 98$ & 30 & 45 & 2.5 \\
October & Gill net & 131 & $667 \pm 42$ & 23 & 18 & 1.5 \\
May-June & 280 & $612 \pm 65$ & 240 & 86 & 10.8 \\
July-October & 216 & $650 \pm 69$ & 69 & 28 & 2.2 \\
May-October & 496 & $629 \pm 69$ & 309 & 62 & 8.9 \\
\hline
\end{tabular}

771 TABLE 2. Total and per capita prey biomass and total and per capita frequency of occurrence of

772 prey consumed by Lake Trout during each month of 2016. Lake Trout total lengths ranged from

773408 to $881 \mathrm{~mm}(\mathrm{~N}=309)$. Statistics are also provided for the May-June and July-October

774 sampling periods.

775

\begin{tabular}{|c|c|c|c|c|c|c|c|}
\hline \multirow[t]{2}{*}{ Month } & \multirow[t]{2}{*}{ Prey species } & \multicolumn{3}{|c|}{ Prey biomass } & \multicolumn{3}{|c|}{ Frequency of occurrence } \\
\hline & & Total (g) & Per capita (g) & Percent & Total & Per capita & Percent \\
\hline \multirow[t]{5}{*}{ May } & Alewife & 2948 & 14.0 & 21 & 1168 & 5.6 & 47 \\
\hline & Round Goby & 10497 & 50.0 & 76 & 1250 & 6.0 & 51 \\
\hline & Lake Trout & 268 & 1.3 & 2 & 13 & 0.1 & 1 \\
\hline & Rainbow Smelt & 116 & 0.6 & 1 & 31 & 0.1 & 1 \\
\hline & Other fish & 26 & 0.1 & 0 & 10 & 0.0 & 0 \\
\hline \multirow[t]{5}{*}{ June } & Alewife & 169 & 5.6 & 14 & 30 & 1.0 & 26 \\
\hline & Round Goby & 1002 & 33.4 & 86 & 86 & 2.9 & 74 \\
\hline & Lake Trout & 0 & 0 & 0 & 0 & 0 & 0 \\
\hline & Rainbow Smelt & 0 & 0 & 0 & 0 & 0 & 0 \\
\hline & Other fish & 0 & 0 & 0 & 0 & 0 & 0 \\
\hline
\end{tabular}




\begin{tabular}{|c|c|c|c|c|c|c|}
\hline Alewife & 905 & 56.6 & 95 & 34 & 2.1 & 89 \\
\hline Round Goby & 8 & 0.5 & 1 & 1 & 0.1 & 3 \\
\hline Lake Trout & 0 & 0 & 0 & 0 & 0 & 0 \\
\hline Rainbow Smelt & 37 & 2.3 & 4 & 2 & 0.1 & 5 \\
\hline Other fish & 4 & 0.3 & 0 & 1 & 0.1 & 3 \\
\hline Alewife & 1474 & 49.1 & 81 & 48 & 1.6 & 64 \\
\hline Round Goby & 219 & 7.3 & 12 & 16 & 0.5 & 21 \\
\hline Lake Trout & 48 & 1.6 & 3 & 1 & 0 & 1 \\
\hline Rainbow Smelt & 81 & 2.7 & 4 & 10 & 0.3 & 13 \\
\hline ther fish & 8 & 0.3 & 0 & 1 & 0 & 1 \\
\hline \multirow{5}{*}{ bow Smelt } & 305 & 13.3 & 83 & 29 & 1.3 & 83 \\
\hline & 27 & 1.2 & 7 & 5 & 0.2 & 14 \\
\hline & 36 & 1.5 & 10 & 1 & 0 & 3 \\
\hline & 0 & 0 & 0 & 0 & 0 & 0 \\
\hline & 0 & 0 & 0 & 0 & 0 & 0 \\
\hline \multirow{5}{*}{$\begin{array}{ll}\text { May-June } & \text { Alewife } \\
& \text { Round Goby } \\
& \text { Lake Trout } \\
\text { Rainbow Smelt }\end{array}$} & 3117 & 13.0 & 21 & 1198 & 5.0 & 46 \\
\hline & 11499 & 47.9 & 76 & 1336 & 5.6 & 52 \\
\hline & 268 & 1.1 & 2 & 13 & 0.1 & 1 \\
\hline & 116 & 0.5 & 1 & 31 & 0.1 & 1 \\
\hline & 26 & 0.1 & 0 & 10 & 0.0 & 0 \\
\hline \multirow{5}{*}{$\begin{array}{ll}\text { July-October } & \text { Alewife } \\
& \text { Round Goby } \\
& \text { Lake Trout } \\
& \text { Rainbow Smelt } \\
& \text { Other fish }\end{array}$} & 2684 & 38.9 & 85 & 111 & 1.6 & 75 \\
\hline & 254 & 3.7 & 8 & 22 & 0.3 & 15 \\
\hline & 83 & 1.2 & 3 & 2 & 0.0 & 1 \\
\hline & 118 & 1.7 & 4 & 12 & 0.2 & 8 \\
\hline & 12 & 0.2 & 0 & 2 & 0.0 & 1 \\
\hline
\end{tabular}

This article is protected by copyright. All rights reserved 
777 TABLE 3. Diet schedule of Lake Trout calculated by averaging the proportional diet

778 composition, based on prey biomass, across all individual Lake Trout for both the May-June

779 period and the July-October period of 2016. Proportions over the entire May-October period

780 were calculated by the weighted average between the May-June and July-October periods,

781 weighting by the number of months within each period. Entries in the table are expressed as

782 percentages. Each column sums to $100 \%$.

783

784

\begin{tabular}{lrrr}
\hline Diet item & May-June & July-Oct & May-Oct \\
\hline Small Alewife $(\leq 120 \mathrm{~mm})$ & $\% 27.3$. & 31.4. & 30.0. \\
Large Alewife $(>120 \mathrm{~mm})$ & 3.5. & 44.4. & 30.8. \\
Lake Trout & 1.3. & 3.1. & 2.5. \\
Round Goby & 66.8. & 14.3. & 31.8. \\
Rainbow Smelt & 1.0. & 5.6. & 4.1. \\
Other & 0.1. & 1.2. & 0.8. \\
\hline
\end{tabular}

785

786

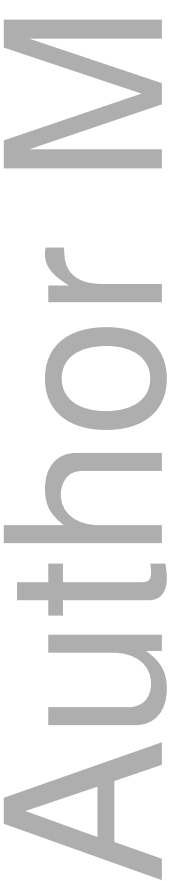




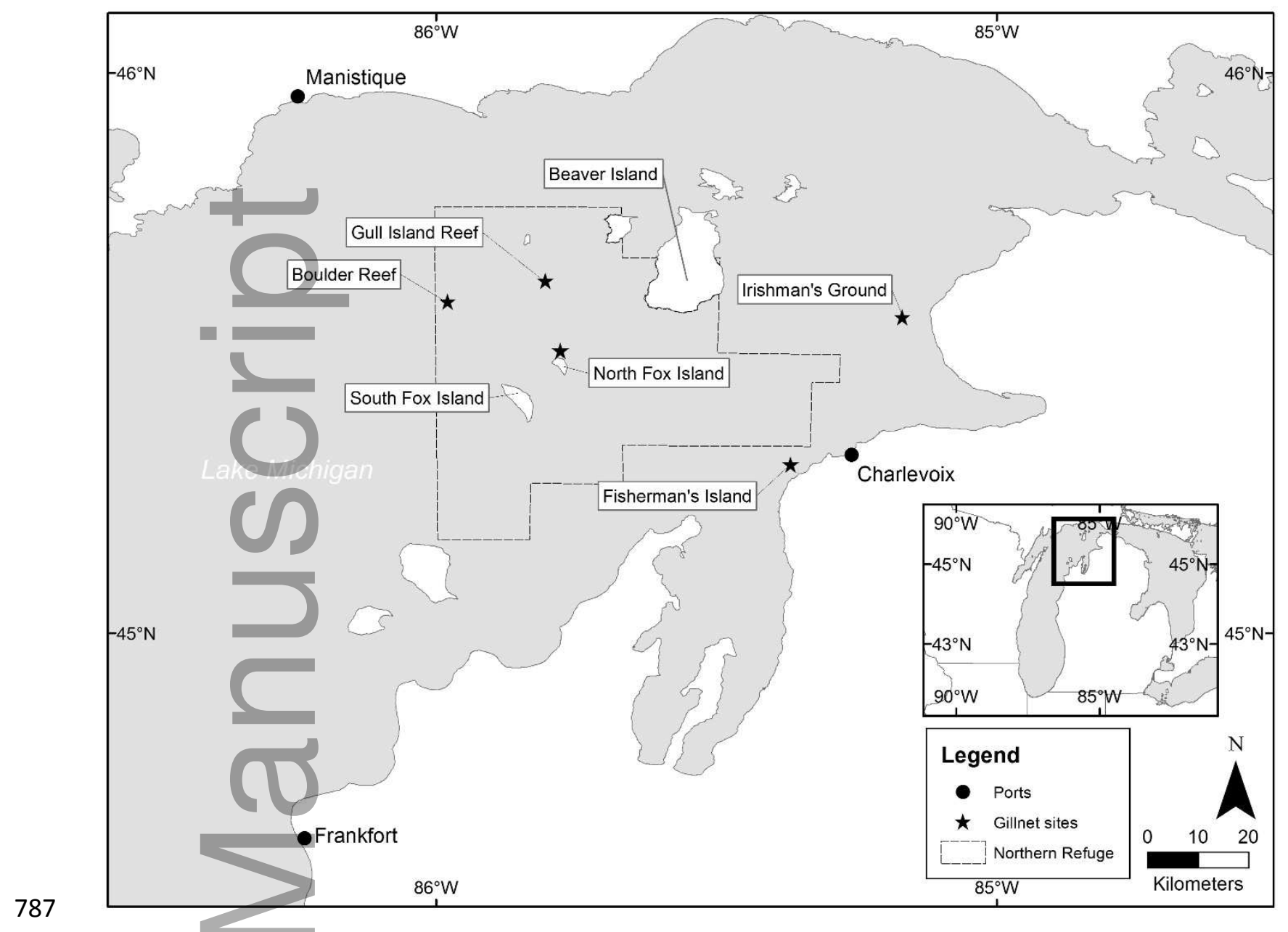

788 FIGURE 1. Map of 2016 sampling locations throughout northeastern Lake Michigan. Lake

789 Trout were caught by anglers at the ports of Manistique, Charlevoix, and Frankfort.

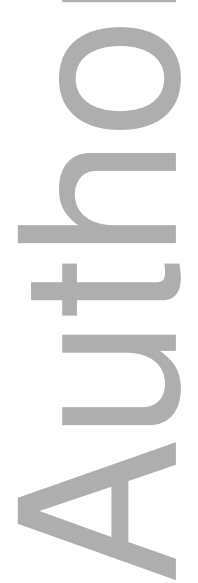




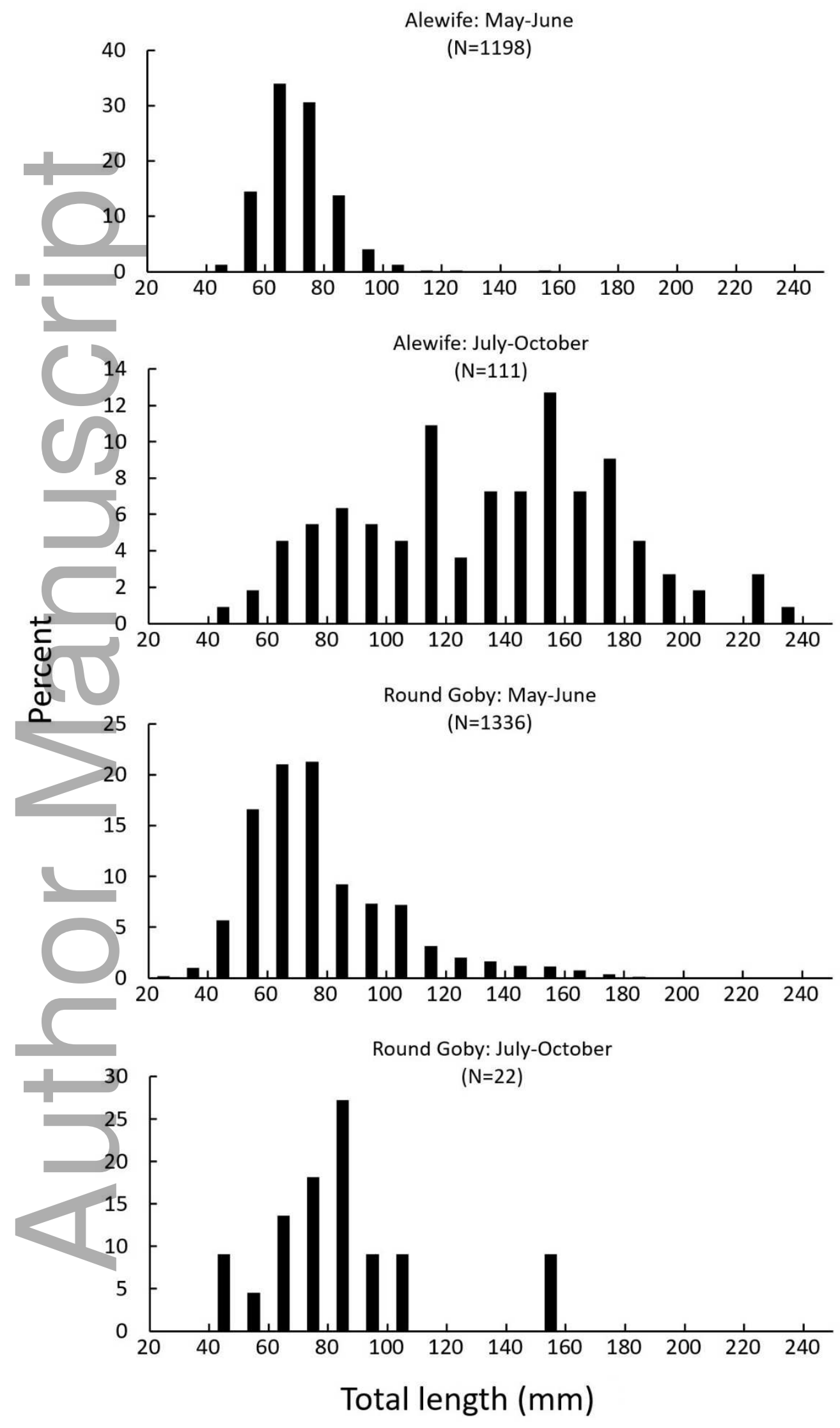

This article is protected by copyright. All rights reserved 
792 FIGURE 2. Total length (TL) frequency distributions of Alewife and Round Goby found in 793 stomachs of Lake Trout caught in Lake Michigan in 2016. Stomachs were pooled by period 794 (May-June and July-October). TLs were measured directly, when possible, or calculated from 795 linear regressions used to convert backbone lengths or standard lengths to TLs.

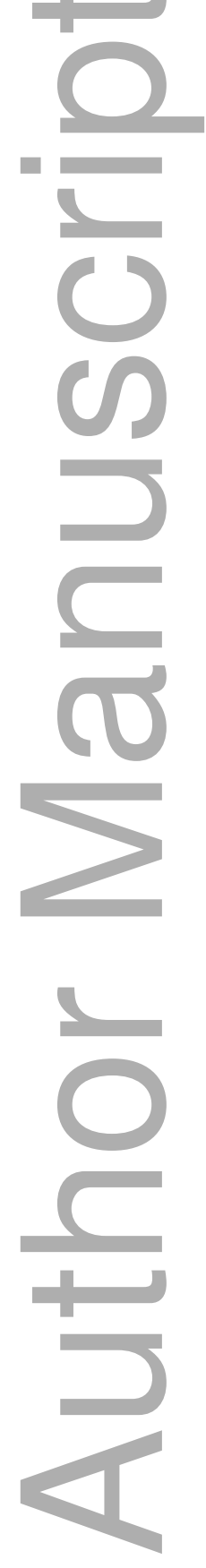

